\title{
Entre el amor romántico y el confluente: representaciones sociales del amor en jóvenes lesbianas de la clase alta limeña
}

\author{
Micaela Giesecke*
}

* Licenciada en Sociología por la Pontificia Universidad Católica del Perú. Actualmente se desempeńa como predocente de la PUCP, y como evaluadora en la Dirección de Licenciamiento de Superintendencia Nacional de Educación Superior (Sunedu). Correo electrónico: micaela.giesecke@ gmail.com

Fecha de recepción: 02/10/2018. Fecha de aceptación: 25/04/2019 


\title{
Entre el amor romántico y el confluente: representaciones sociales del amor en jóvenes lesbianas de la clase alta limeńa
}

\section{RESUMEN}

El amor ha sido materia de discusión en diversas áreas del conocimiento, el arte y la vida cotidiana. Desde la sociología, la presente se pregunta por las representaciones sociales en torno al amor de las jóvenes lesbianas de sectores altos de Lima, así como por la influencia de sus trayectorias personales, familiares y autoidentificación en la construcción de tales representaciones. Para responder estas y otras interrogantes, se aplicaron entrevistas a nueve jóvenes lesbianas pertenecientes a los sectores altos de Lima y se analizaron sus relatos biográficos desde la sociología de la estructuración social, el posestructuralismo y el enfoque de género. Se hallaron dos aproximaciones al amor entre las jóvenes: del amor romántico al confluente y hacia el amor confluente. Este amor, además, guarda tres secretos: en el mundo interno, con el entorno y con la pareja. Lo ya mencionado se vincula, entre otros factores, con la especificidad de su posición social en los sectores altos y su orientación sexual.

Palabras clave: lesbiana, LGTBIQ, representaciones sociales, amor romántico, amor confluente, clase alta

\section{Between romantic and confluent love: social representations of love among young lesbians from Lima's upper class}

\begin{abstract}
Love has been subject of interest to various areas of knowledge, art and everyday life. From the field of sociology, this paper aims to analyze social representations of love among young lesbians of Lima's upper class. The focus is on how their trajectories, families and self-identification influence the construction of such representations. Nine interviews were conducted with young lesbians from the upper class to answer the research question. Two approaches to love were found: from romantic to confluent love and towards confluent love. Moreover, it was found that this love holds three secrets: the secret of the inner world, the secret that is kept from their families and the environment and the one that is hidden from their partners. The aforementioned is linked, among other factors, to the specificity of being lesbians from Lima’s upper class.
\end{abstract}

Keywords: lesbian, LGTBIQ, social representations romantic love, confluent love, upper class 


\section{INTRODUCCIÓN}

El amor, las relaciones de pareja y la vivencia de la intimidad son aspectos intrínsecos a la humanidad. Su práctica se ve influida por el espacio y el contexto donde se ubican los individuos, así como por sus subjetividades. Estas últimas son mediadas por los cambios globales en los ámbitos cultural, social y político (Giddens, 1995; Bauman, 2005; Beck y Beck, 2001). Se ha estudiado, también, la influencia del capitalismo en la mercantilización del amor (Illouz, 2009) o, en otras palabras, cómo este se consume y pone en práctica. Autores como Herrera (2010), Giddens (1995) o Bauman (2005) se han dedicado al estudio del amor y han propuesto tipologías del mismo en occidente. El amor romántico, según Herrera (2010), es una construcción sociocultural vinculada con la ideología patriarcal que «influye, conforma y modela las estructuras organizativas colectivas humanas» (p. 76). Es el predominante, según la autora, en sociedades occidentales. Se trata de un sentimiento individual con implicancias en la organización social, concebido como eterno, mágico, apasionado, monógamo y basado en la familia nuclear tradicional.

El amor confluente, por su parte, surge a partir de las transformaciones en la intimidad y relaciones de género más democráticas. Se basa en la búsqueda de la satisfacción de las partes involucradas en la relación en los ámbitos afectivo y sexual (Giddens, 1995). Se sostiene en la búsqueda del conocimiento sobre la pareja y en no asumir que la relación será eterna; tampoco tiene como fin el matrimonio. Se trata de un proyecto democrático donde se negocian acuerdos y se prioriza el desarrollo individual. En sociedades occidentales posmodernas, sostiene Bauman (2005), a diferencia de lo propuesto por los autores mencionados, se experimenta el amor líquido, donde las relaciones afectivas se construyen frágilmente ante la necesidad de los sujetos por tener seguridad en un mundo donde las instituciones y estructuras ya no la brindan. Dicho anhelo convive con tres temores: ser una carga para la pareja, no tener libertad para conseguir metas individuales y no poder vincularse romántica o sexualmente con distintas personas. El amor, la sexualidad, la paternidad y la familia dejan de ser centrales en los proyectos de vida personales. Los lazos sociales se vuelven frágiles y producen inseguridades y tensiones por las ansias de forjarlos, pero mantenerlos flojos.

En América Latina, no obstante, el amor ha sido estudiado en jóvenes heterosexuales (Rodríguez y Pérez, 2006; García, 2013; Ilizarbe, 1999; Menéndez, 2014). La evidencia da cuenta de la permanencia de los ideales del amor romántico, así como de los esfuerzos de los jóvenes por poner en práctica un amor del tipo confluente (Giddens, 1995). Sin embargo, poco se sabe sobre las subjetividades de individuos con orientaciones sexuales diversas, y particularmente lésbicas, en el marco de sus vivencias amorosas. En esa línea, pese a que las transformaciones demográficas en 
el Perú ${ }^{1}$ den cuenta de la influencia de los cambios culturales en los ámbitos global y local (Aramburú, 2012; Sara-Lafosse, 2012), la población LGBTIQ², de orientaciones sexuales «disidentes» de la norma heterosexual, continúan en la búsqueda del reconocimiento de derechos para vivir sus afectos libremente. El 61\% de la población nacional rechaza la unión civil homosexual y el 74\% el derecho a la adopción en parejas homosexuales (Ipsos, 2014a). Esto se debe, en parte, a que la sexualidad es biologizada y entendida solo por su función reproductiva, para preservar la especie y el orden social. Lo anterior supone una sola forma de unión: la heterosexual (Faur y Grimson, 2016, p. 113), y hace frente a la diversidad sexual y de género existente.

Este estudio representa un aporte a lo que se conoce hasta hoy sobre juventudes y subjetividades lésbicas, con la especificidad de pertenecer al sector alto. Como sostienen Fuller (1993) y Kogan (2009), en dicho grupo existen resistencias a transgredir los patrones tradicionales de conducta y que suelen ser consideradas como difusoras de valores. Esto teniendo en cuenta que «el modelo y las pautas de control de emociones pueden ser distintos según las clases sociales de que se trate en una sola sociedad» (Elías, 1987, p. 58). Por ello, se buscó profundizar en las subjetividades de jóvenes lesbianas, cuya orientación sexual, inferimos, podría ser un mandato de clase entre los sectores altos. En esta oportunidad, se hará lo ya mencionado desde la aproximación a sus representaciones sociales en torno al amor, así como de los elementos que las configuran y de la incidencia de las trayectorias personales en su configuración. Se dará a conocer, además, cómo se expresan la sexualidad, vida familiar, redes sociales y expectativas en las representaciones, en el marco de una sociedad donde se gestan luchas por la reivindicación de grupos con orientaciones sexuales diversas, al tiempo que se mantienen tradiciones sobre el modo de ser, sentir y actuar. La aproximación metodológica fue cualitativa, pues se buscó interpretar los relatos biográficos en torno a la problemática estudiada y no generalizar.

En este artículo se presenta, en primer lugar, el marco metodológico. Luego, se plantean los hallazgos, donde se sitúa a las participantes del estudio, se analizan las representaciones sociales y la noción del secreto en el amor de las jóvenes lesbianas. Finalmente, se postulan las aproximaciones finales. A lo largo de la presente, me enuncio desde una perspectiva que busca contribuir en el desarrollo de los estudios de género y diversidad sexual, en tanto se trabaja con sujetos que cuestionan las estructuras, el orden binario del género y la heteronormatividad (Butler, 1990).

\footnotetext{
1 Algunos son el descenso de la tasa de fecundidad, la reducción de número de hijos por mujer y el retraso de la edad del matrimonio en el mismo grupo, entre otros,

2 LGBTIQ se refiere a la población de personas (i) no heterosexuales: lesbianas (mujeres que se sienten atraídas por mujeres), gais, bisexuales, pansexuales, entre otras; (ii) cuyo género no corresponde necesariamente a la expectativa que se tiene de ellas por su sexo biológico: transexuales, travestis, de género no binario o queer, y (iii) cuyo aparato reproductivo no coincide con el tradicionalmente definido como masculino o femenino: intersexuales (No tengo miedo, 2016a).
} 
GIESECKE / Entre el amor romántico y el confluente: representaciones sociales del amor en jóvenes lesbianas...

\section{Marco METODOLÓGico}

When we listen to people, do they give us their stories or do we steal them? At the heart of all social investigation is a dialectical tension between theft and gift, appropriation and exchange ${ }^{3}$

(Sharma, 2008, p. 557)

En la presente se buscó responder al problema de investigación mediante el enfoque biográfico (Arfuch, 2002); de ahí que sea de carácter cualitativo (Strauss y Corbin, 2002). Se realizó «una cartografía de la trayectoria —individual - siempre en la búsqueda de sus acentos colectivos» (2002, p. 17) para analizar la información que (re)construyen las participantes del estudio sobre sus experiencias. Se tomaron, también, elementos de la teoría fundamentada (Strauss y Corbin, 2002), para generar conocimiento de manera inductiva, mediante el análisis de las subjetividades. Para ello, se profundizó en el significado de las narrativas de los sujetos, construidas sobre la base de la experiencia social e individual, donde confluyen emociones, sentimientos, prácticas y un entramado de relaciones interpersonales (Yin, 2009). Esto facilitó la realización de un modelo de representaciones sociales que, según Jodelet (2011), son constructos elaborados a partir del sentido común, para entender la vida social y desenvolvernos en ella.

El trabajo de campo se realizó durante once meses, de 2016 a 2017, y tuvo lugar en Lima, Perú. Se realizaron nueve entrevistas de una duración aproximada de tres horas y media, en una o dos sesiones. La selección de las participantes se dio en tanto cumplían con el perfil para la construcción de una muestra teórica (Glaser y Strauss, 1967): todas se autoidentificaron como lesbianas y eran abiertamente homosexuales en sus grupos de pares; tienen entre veinte y veinticuatro años ${ }^{4}$, acudieron a universidades privadas y pertenecen al 4,4\% de la población limeña ubicada en el nivel socioeconómico (NSE) A A $^{5}$ Ipsos, 2014b). Fueron, además, referidas por gatekeepers $^{6}$, que las identificaron como parte del entorno lésbico del sector alto. De ahí

\footnotetext{
3 «Cuando escuchamos a las personas, ¿̨nos dan sus historias o se las robamos? En el corazón de toda investigación social se encuentra la tensión social entre el robo y el regalo, la apropiación y el intercambio». (Traducción propia).

4 Según la OMS (2000), entre los veinte y veinticuatro ańos, tras diversos procesos de la adolescencia, los individuos se identifican sexualmente. Aunque no necesariamente de manera estática, ello da cuenta de un nivel de conocimiento personal que se manifestará en las narrativas de las jóvenes.

5 Las familias de los sectores A y AB se encuentran principalmente en la zona 7 de Lima (Asociación Peruana de Empresas de Inteligencia de Mercados - Apeim, 2016), donde residen las jóvenes (Surco, San Borja, La Molina y Miraflores). Implica un ingreso familiar superior a 10000 soles, contar con todos los servicios y poseer bienes materiales. Estudiaron en colegios y universidades privadas de Lima. Este NSE representa al 5\% de las mujeres limeñas entre veinte y veinticuatro años (INEI, 2016).

6 Las gatekeepers son amigas o colegas de la investigadora, de distintos ámbitos. Así se evitó estudiar la experiencia particular de una red de amigas, hecho que podría haber resultado de contactar a las participantes mediante la «bola de nieve».
} 
que, al contactarlas, sientan confianza para unirse al proyecto y compartir experiencias tan íntimas con quien escribe. En la tabla 1 se presenta a las jóvenes ${ }^{7}$.

Tabla 1. Participantes del estudio

\begin{tabular}{llcl}
\hline $\mathbf{N}^{\circ}$ & Nombre & Edad & Ocupación \\
\hline $\mathbf{1}$ & Thaís & 24 & Comunicaciones \\
$\mathbf{2}$ & Gracia & 22 & Estudiante \\
$\mathbf{3}$ & Lorena & 24 & Comunicaciones \\
$\mathbf{4}$ & Paula & 22 & Estudiante \\
$\mathbf{5}$ & Antonella & 20 & Estudiante \\
$\mathbf{6}$ & Ivanna & 24 & Estudiante \\
$\mathbf{7}$ & Jacquie & 23 & Estudiante \\
$\mathbf{8}$ & Romina & 24 & Recursos humanos \\
$\mathbf{9}$ & Carolina & 22 & Estudiante \\
\hline
\end{tabular}

Para abordar temas en los que pueden no haber reflexionado antes o que no suelen tocar con sus familias, amigxs ${ }^{8}$ o pareja, se cuidaron dos aspectos. En primer lugar, el setting de las entrevistas se adecuó a la preferencia de las jóvenes por espacios abiertos, donde pudieran exteriorizar aquello que no suelen nombrar sin temor a ser escuchadas, como parques o jardines; o lejos de la escucha y mirada de terceros, en el caso de espacios cerrados como cafés y restaurantes. En segundo lugar, la desobjetivación de las participantes tiene que ver con que las entrevistas y el análisis se realicen por y con el objeto de estudio (Segato, 2011, p. 18). Se minimizaron las asimetrías entre entrevistadora y jóvenes mediante el ejercicio de reflexividad, que implica la autoconciencia y reducción de las distancias entre ambas en la entrevista9 (Haraway, 1991; Bourdieu, 1999), empleando el lenguaje que surgiera en la conversación, aprovechando la similitud en las edades entre ambas partes y la posibilidad de reconocimiento en mutuo. Se gestionó un ambiente horizontal, cómodo y de libre expresión para no robar las historias a las jóvenes, sino (re)construir con ellas sus relatos y generar una comunicación no violenta en un plano simbólico

\footnotetext{
Se emplearon nombres distintos de los reales para mantener la confidencialidad.

8 Como parte de una investigación enmarcada en los estudios de género y diversidad sexual, se empleó un lenguaje inclusivo, para cuyo fin se empleó la «X» en lugar de la "a» $\mathrm{u}$ «o» del femenino o masculino.

9 En esta oportunidad, por NSE, orientación sexual y rol en la entrevista. Para ello se escuchó con atención y se procuró minimizar las asimetrías entre investigadora y entrevistada a partir de la escucha activa, el lenguaje hablado y corporal, el tono de voz y la vestimenta, entre otros factores.
} 
(Bourdieu, 1999). Todo esto para elaborar un «conocimiento situado», que diste de pretensión de la universalización teórica (Haraway, 1991).

\section{CONOCIENDO A LAS NUEVE JÓVENES}

Thaís, Gracia, Lorena, Paula, Antonella, Ivanna, Jacquie, Romina y Carolina son las integrantes de este estudio. Salvo Romina y Gracia, no son hijas únicas. Los padres de la mayoría están casados por vía civil y religiosa. Sus relaciones no se caracterizan por el amor, sino por el compañerismo. La mayoría ha enfrentado separaciones o momentos críticos por infidelidades o desacuerdos, entre otros motivos que llevaron a algunas jóvenes a distanciarse del padre como figura protectora y afectiva. Los padres de dos de las jóvenes mantuvieron su relación a distancia en un inicio. Se mandaban cartas y se visitaron hasta casarse y establecerse en el Perú. En este caso, quien vivió fuera del Perú mantiene una visión más abierta con respecto a la homosexualidad de sus hijas, comentaban Thaís e Ivanna.

Sus padres nacieron en Lima, con excepción de los de Romina y Antonella, cuyos padres son de otros departamentos del Perú. El padre de Carolina fue el único que residió en el extranjero gran parte de su vida. Todos tienen estudios universitarios, aunque dos no los concluyeron por insertarse exitosamente en el mundo empresarial. La mayoría se dedica a los negocios, salvo en el caso de los padres de Paula y Gracia. Según comentaron las jóvenes, la mayoría de padres tiene actitudes sexistas u homofóbicas, por lo que los consideran machistas. De otro lado, salvo la madre de Thaís, que nació y creció en el extranjero, todas son limeñas. Algunas vivieron períodos largos fuera de Perú y todas tienen estudios universitarios o técnicos completos. Se evidenció la doble carga laboral, en el hogar y mercado laboral, que deben llevar algunas de las madres, mientras que otro grupo se dedica exclusivamente a sí mismas, con actividades como aprender idiomas, ir al gimnasio o a la peluquería. Predominan, también, ideas conservadoras con respecto a cuestiones sociales y de género, con mandatos que suelen vincularse a la matriz heterosexual (Butler, 1990). Los padres menos machistas y las madres más abiertas de mente, comentaron las jóvenes, fueron más receptivos cuando les contaron de su homosexualidad.

La tabla 2 resume lo ya señalado, presenta la conformación de sus redes sociales y su autoidentificación a partir de la orientación sexual y, de ser el caso, de género.

Como se puede ver, todas estudiaron en colegios particulares, ya sean mixtos o solo de mujeres. La mayoría recibió educación bilingüe y religiosa. La educación sexual, de haberla habido, partía de un enfoque biologicista y heteronormado. Todas llevaron a cabo sus estudios de pregrado en universidades privadas de Lima, en carreras de ciencias humanas, hospitalarias, de la comunicación y administración. 
Tabla 2. Biografías

\begin{tabular}{|c|c|c|c|}
\hline Nombre & Familia & Redes & Autoidentificación \\
\hline Thaís & $\begin{array}{l}\text { Madre extranjera, padre } \\
\text { Lima, Perú. } \\
\text { Casados: buena relación. }\end{array}$ & $\begin{array}{l}\text { Relaciones amorosas de amigas les- } \\
\text { bianas distintas a heterosexuales. } \\
\text { No amigas activistas, universidad, } \\
\text { colegio, otros. }\end{array}$ & $\begin{array}{l}\text { Leca } \\
\text { Secundaria }\end{array}$ \\
\hline Gracia & $\begin{array}{l}\text { Padres de Lima, Perú. } \\
\text { Casados: relación conflic- } \\
\text { tiva. No enamorados. }\end{array}$ & $\begin{array}{l}\text { Pocas referencias de relaciones amo- } \\
\text { rosas de amigas lesbianas. } \\
\text { Amigas ciberactivistas y activistas, } \\
\text { colegio, universidad, otros. }\end{array}$ & $\begin{array}{l}\text { Leca o lesbiana } \\
\text { Universidad }\end{array}$ \\
\hline Lorena & $\begin{array}{l}\text { Padres de Lima, Perú. } \\
\text { Casados: relación conflic- } \\
\text { tiva. No enamorados. }\end{array}$ & $\begin{array}{l}\text { Relaciones amorosas de amigas les- } \\
\text { bianas tienen otras prioridades que } \\
\text { las heterosexuales. } \\
\text { No amigas activistas, universidad, } \\
\text { vecinos, otros. }\end{array}$ & $\begin{array}{l}\text { Leca o ninguna } \\
\text { Secundaria }\end{array}$ \\
\hline Paula & $\begin{array}{l}\text { Padres de Lima, Perú. } \\
\text { Madre vivió en el } \\
\text { extranjero. } \\
\text { Casados: relación conflic- } \\
\text { tiva. No enamorados. }\end{array}$ & $\begin{array}{l}\text { Relaciones amorosas de amigas les- } \\
\text { bianas "densas" dentro del pequeño } \\
\text { grupo. } \\
\text { Amigas ciberactivistas, colegio, uni- } \\
\text { versidad, trabajo, otros. }\end{array}$ & $\begin{array}{l}\text { Leca } \\
\text { Secundaria }\end{array}$ \\
\hline Antonella & $\begin{array}{l}\text { Padres provincia de Perú. } \\
\text { Separados: } \quad \text { relación } \\
\text { conflictiva. }\end{array}$ & $\begin{array}{l}\text { Pocas referencias de relaciones amo- } \\
\text { rosas de amigas lesbianas. } \\
\text { Amigas ciberactivistas, universidad, } \\
\text { vecindario, colegio, deportes, otros. }\end{array}$ & $\begin{array}{l}\text { Leca } \\
\text { Andrógino } \\
\text { Universidad }\end{array}$ \\
\hline Ivanna & $\begin{array}{l}\text { Padres de Lima, Perú. } \\
\text { Madre vivió en el } \\
\text { extranjero. } \\
\text { Casados: relación muy } \\
\text { buena. }\end{array}$ & $\begin{array}{l}\text { Relaciones amorosas de amigas les- } \\
\text { bianas largas, intensas y dentro del } \\
\text { pequeño grupo. } \\
\text { Colegio, universidad, otros. }\end{array}$ & $\begin{array}{l}\text { Leca } \\
\text { Secundaria }\end{array}$ \\
\hline Jacquie & $\begin{array}{l}\text { Padres de Lima, Perú. } \\
\text { Separados: relación } \\
\text { conflictiva. }\end{array}$ & $\begin{array}{l}\text { Relaciones amorosas de amigas } \\
\text { lesbianas más "densas" que hetero- } \\
\text { sexuales y dentro del pequeño grupo. } \\
\text { Amigas ciberactivistas, colegio, uni- } \\
\text { versidad, otros. }\end{array}$ & $\begin{array}{l}\text { Leca } \\
\text { Universidad }\end{array}$ \\
\hline Romina & $\begin{array}{l}\text { Madre de Lima, Perú. } \\
\text { Padre de provincia de } \\
\text { Perú. } \\
\begin{array}{l}\text { Divorciados: relación } \\
\text { conflictiva. }\end{array}\end{array}$ & $\begin{array}{l}\text { Relaciones amorosas de amigas les- } \\
\text { bianas largas, "densas" y dentro del } \\
\text { pequeño grupo. } \\
\text { Amigas ciberactivistas, colegio, uni- } \\
\text { versidad, vecinas, deportes, otros. }\end{array}$ & $\begin{array}{l}\text { Leca } \\
\text { Andrógino } \\
\text { Universidad }\end{array}$ \\
\hline Carolina & $\begin{array}{l}\text { Padres de Lima, Perú. } \\
\text { Padre vivió en el } \\
\text { extranjero. } \\
\text { Casados: relación muy } \\
\text { buena. }\end{array}$ & $\begin{array}{l}\text { Relaciones amorosas de amigas les- } \\
\text { bianas largas, “densas" y dentro del } \\
\text { pequeño grupo. } \\
\text { Amigas ciberactivistas, colegio, uni- } \\
\text { versidad, deportes, trabajo, otros. }\end{array}$ & $\begin{array}{l}\text { Leca } \\
\text { Secundaria }\end{array}$ \\
\hline
\end{tabular}


Actualmente, todas se encuentran en el tránsito de la vida universitaria a la laboral, por lo que siguen disponiendo de poco tiempo libre, que emplean en actividades culturales como ver series, ir al teatro o cine, así como en asistir a fiestas gay. La expansión y el consumo de productos culturales cuya temática, personajes o actores fueran homosexuales, sostuvo Martel (2013), impulsó a muchas personas alrededor del mundo a salir del clóset, incluso en sociedades conservadoras (pp. 288-294). De ahí que Thaís haya encontrado en su hermana apoyo y conocimiento respecto de la homosexualidad cuando le comentó al respecto: "Oye, tengo algo que contarte'[...] 'ah, que estoy con Ariana’ y me dijo, '¡ah, sí sabía!', y le dije, '¡ah? y ¿̇todo bien?’ y me dijo ‘¡sí, obvio! veo Glee’» (Thaís, 24 años).

Todas asisten a fiestas o bares gay con sus pares, que forman parte también de la comunidad LGTBIQ. Conocieron a sus amigxs más cercanxs, con quienes acuden a estos espacios, en el colegio, universidad u otros espacios, y a sus redes LGTBIQ más extensas a través de su grupo más próximo o de sus ex parejas. Las jóvenes mantienen relaciones sexuales y afectivas homógamas (Maenpaa y Jalovaara, 2013), es decir, sus parejas son de su entorno social y económico; además, suelen tener un bagaje cultural similar al suyo. Ellas afirman que el círculo es pequeño: «El mundo gay de Lima es chico o, al menos, eso creo yo. Conoces un montón de gente que siempre asiste a los mismos lugares» (Paula, 22 años). De ahí que el habitus de las jóvenes influya en la "distinción» entre aquellas que podrán acceder a estos espacios de quienes no, y será con las primeras con quienes, finalmente, se relacionarán. Además, se sienten más cómodas en un ambiente LGTBIQ, pues no hay hombres heterosexuales que las observen bailar y las hostiguen: «En las fiestas heterosexuales, si es que yo voy con mi novia, y ponte que nos ponemos a chapar o abrazar, vienen chicos, ¿no? y te dicen como que 'ah, hay que juntarnos los tres'» (Paula, 22 años). Adicionalmente, se encuentra el hecho de que no precisan encajar en los roles de género ni en las normas de vestimenta típicamente femeninas. No se sienten presionadas a vestir tacos o ropa apretada, comentaba Romina (24 años).

Las nueve jóvenes «salieron del clóset», es decir, se autoidentificaron con el resto como lesbianas, en el tránsito de la secundaria a la universidad. Pueden haber sentido atracción por una mujer previamente, sin embargo, como comenta una de ellas: «No fue tanto como que 'yo soy, yo pienso que soy lesbiana', no; sino que, en el acto, yo me daba... me daba cuenta de que a mí me gustaban las mujeres enteramente" "(Carolina, 22 años). Algunas comentaron que tuvieron experiencias heterosexuales andes de ese momento, no necesariamente placenteras. También se hizo explícito el malestar generado al no poder conversar con nadie sobre lo que sentían, hecho que las limitaba de pensarse como lesbianas, comentaba Ivanna: «Un adolescente enamorado de por sí sufre, porque sientes inseguridad, y sientes todas las cosas que te inundan y no entiendes y te, y te poseen. Imagínate toda esa 
situación, pero no poder aceptarla. O sea, no poder decir 'estoy enamorado', o no... no poder entenderlo así. Yo no podía estar enamorada porque era mi mejor amiga, entonces eso no podía existir» (Ivanna, 24 años).

Salvo Gracia, todas se autoidentifican como «leca», pues dicha categoría no tiene la carga que «lesbianas» sí, sostenía Paula (22 años): «Se me hace difícil la palabra 'lesbiana', no sé por qué. O sea, no me gusta. Suena fuerte, no sé por qué. Prefiero decir: 'soy gay' [...] Ahora ya me digo 'leca', ¿̇manyas? Mucho más fresh». Tampoco las encasilla en un marco de atributos ni les asigna estereotipos automáticamente como la palabra «lesbiana»: «Es como que te ponen en una categoría. Y esa categoría significa una serie de cosas, entonces, asumen que tú significas esa serie de cosas» (Ivanna, 24 ańos). Como se puede observar en la narrativa de Paula, incluso identificarse como gay, que refiere a hombres homosexuales, es más aceptado por ellas. Además, la mayoría ve su sexualidad como fluida y no se cierra a la posibilidad de involucrarse sexual o afectivamente con hombres. Dos de las jóvenes se autoidentifican, además, como no binarias o andróginas. Sin embargo, no verse femeninas es un indicador para el resto, que evalúa a las jóvenes a partir del binario de género (Butler, 1990) de su sexualidad o del rol que llevan a cabo en sus relaciones. Dentro de la comunidad son categorizadas como "tomboy» ${ }^{10}$. En la tabla 3 se resume lo ya mencionado.

Dos hechos caracterizan el inicio de la vida sexual de las jóvenes. En primer lugar, que se dio en espacios LGTBIQ friendly ${ }^{11}$, donde no se cuestionaba la transgresión de la norma heterosexual y las jóvenes encontraban tranquilidad para experimentar sus afectos lésbicos. En segundo lugar, por la presencia del consumo de alcohol en las narrativas: «En una fiesta, estaba muy muy borracha porque si no, no me hubiera atrevido. La saqué a bailar... Y empezamos a bailar y chapamos ${ }^{12}{ }_{\eta}$. Ambos elementos, el consumo de alcohol y el cuidado de no exponerse abiertamente como lesbianas en el espacio público o en lugares heteronormados, son "tecnologías del yo» (Foucault, 2008) desarrolladas por las jóvenes para no transgredir los valores y pautas de clase y género que les son asignadas. De ahí también que no todas sean abiertamente lesbianas en el ámbito familiar. Aquellas que sí lo contaron a sus familias, tienen su respaldo y que se reconozcan como «privilegiadas» por no ser discriminadas: «Todos los días hay casos de personas que han sido discriminadas por ser gais, por vivir su sexualidad, entonces como que me suena irreal porque nunca me pasa» (Paula, 22 años). Ni aquellas que tienen el respaldo de sus familias, ni

Masculina.

11 Amigable con la población LGTBIQ.

12 Acto de besarse. 
Tabla 3. Autoidentificación y amor lésbico

\begin{tabular}{llllll}
\hline Nombre & $\begin{array}{l}\text { Momento } \\
\text { autoiden- } \\
\text { tificación }\end{array}$ & $\begin{array}{l}\text { Inicio } \\
\text { enamoramiento } \\
\text { mujeres }\end{array}$ & $\begin{array}{l}\text { Estatus } \\
\text { sentimental }\end{array}$ & Duración & Observaciones \\
\hline Thaís & Secundaria & $\begin{array}{l}\text { Primeros años } \\
\text { universidad }\end{array}$ & Enamorada & Meses & $\begin{array}{l}\text { Relación a } \\
\text { distancia }\end{array}$ \\
\hline Gracia & $\begin{array}{l}\text { Primeros años } \\
\text { universidad }\end{array}$ & $\begin{array}{l}\text { Últimos años } \\
\text { universidad }\end{array}$ & Enamorada & Meses & $\begin{array}{l}\text { Primera } \\
\text { enamorada }\end{array}$ \\
\hline Lorena & $\begin{array}{l}\text { Secundaria - } \\
\text { Primeros años } \\
\text { universidad }\end{array}$ & $\begin{array}{l}\text { Últimos años } \\
\text { universidad }\end{array}$ & Enamorada & Años & $\begin{array}{l}\text { Segunda } \\
\text { enamorada }\end{array}$ \\
\hline Paula & Secundaria & $\begin{array}{l}\text { Primeros años } \\
\text { secundaria }\end{array}$ & Enamorada & $\begin{array}{l}\text { Año y } \\
\text { meses }\end{array}$ & $\begin{array}{l}\text { Segunda } \\
\text { enamorada }\end{array}$ \\
\hline Antonella & $\begin{array}{l}\text { Primeros años } \\
\text { universidad }\end{array}$ & $\begin{array}{l}\text { Últimos años } \\
\text { universidad }\end{array}$ & Soltera & Año & $\begin{array}{l}\text { Sigue } \\
\text { enamorada de } \\
\text { su ex pareja }\end{array}$ \\
\hline Ivanna & Secundaria & $\begin{array}{l}\text { Últimos años } \\
\text { universidad }\end{array}$ & Enamorada & Años & $\begin{array}{l}\text { En relación a } \\
\text { distancia }\end{array}$ \\
\hline Jacquie & $\begin{array}{l}\text { Primeros años } \\
\text { universidad }\end{array}$ & $\begin{array}{l}\text { Primeros años } \\
\text { universidad }\end{array}$ & Soltera & Años & $\begin{array}{l}\text { No ha tenido } \\
\text { enamorada }\end{array}$ \\
\hline Romina & $\begin{array}{l}\text { Primeros años } \\
\text { universidad }\end{array}$ & $\begin{array}{l}\text { Primeros años } \\
\text { universidad }\end{array}$ & Enamorada & $\begin{array}{l}\text { Año y } \\
\text { meses }\end{array}$ & $\begin{array}{l}\text { En relación } \\
\text { con un hombre }\end{array}$ \\
\hline Carolina & Secundaria & $\begin{array}{l}\text { Primeros años } \\
\text { universidad }\end{array}$ & Enamorada & $\begin{array}{l}\text { Año y } \\
\text { meses }\end{array}$ & $\begin{array}{l}\text { Convivieron } \\
\text { por un tiempo }\end{array}$ \\
\hline
\end{tabular}

quienes no han salido del clóset con ellas, pertenecen a redes activistas que buscan cambiar la situación descrita previamente. Parte de esto puede tener que ver con la necesidad de protegerse ante las miradas del resto, que las vigilan por transgredir las normas de clase y género que les son asignadas, tal como ocurre cuando el inicio de su vida sexual se da en espacios LGTBIQ friendly y bajo el consumo de sustancias alcohólicas. Es preciso mencionar, no obstante, que algunas de ellas hacen ciberactivismo (Ugarte, 2007) o realizan lo que denominan «activismo cotidiano», mediante conversaciones educativas sobre el tema de género y diversidad sexual.

Es preciso mencionar que, cuando las jóvenes viajan fuera del país, se sienten más a gusto que en Lima respecto de la expresión de su sexualidad. Como sostuvo Martel (2013), en ciudades con más apertura y aceptación a la homosexualidad, que también cuentan con regulaciones y normativa contra la discriminación por orientación sexual, se desenvolvieron sin temor a ser juzgadas por la sociedad. 


\section{ENTRE EL AMOR ROMÁNTICO Y EL CONFLUENTE: REPRESENTACIONES DEL AMOR}

El amor entre las nueve jóvenes se representa como sentimiento, trabajo, objeto, prácticas, intimidad y justicia. Debido a la diversidad de sus subjetividades, su identificación con las representaciones no es homogénea y difiere tanto en la forma de concebir el amor como en su práctica. Dos tipos de amor predominan en sus representaciones: se trata del amor romántico (Herrera, 2010) y el confluente (Giddens, 1995).

\section{Gráfico 12. Representaciones sociales en torno al amor}

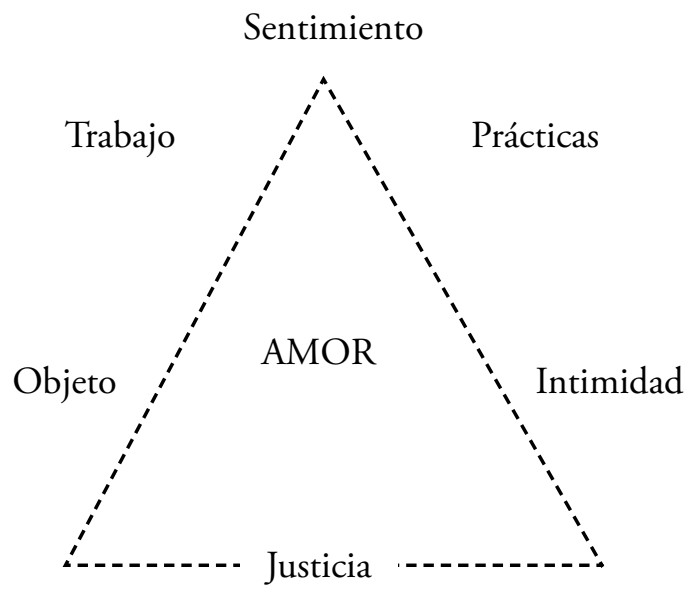

El amor como sentimiento se manifiesta en la satisfacción que trae ser correspondido. Es considerado eterno, excede la racionalización y se entiende como mágico. En palabras de Carolina, «es tan místico, es tan incierto de alguna manera... Como que lo sentimos, pero no sabemos qué es» (22 años). También se manifiesta como plenitud y felicidad, cuando es correspondido: «Es como una mezcla de demasiada felicidad y, a la vez, tranquilidad. Este sentimiento de 'te encontré', de 'eres tú la persona que me da todo y que me hace dar todo’» (Gracia, 22 ańos). El amor puede ser intenso, tanto por los sentimientos ya descritos como por otros tóxicos, tales como los celos ante posibles infidelidades, por inseguridades por no sentirse suficiente para la pareja. Ser densa también es otro atributo asociado negativamente con el amor o el enamoramiento. Es una característica propia de algunas mujeres, comentaban las jóvenes, y se hace evidente cuando dos se unen y una de las partes discute mucho, es insegura o celosa: "Hay bastante intensidad en el mundo gay de mujeres» (Carolina, 22 años). Especialmente, sugerían, esto se debe a que el mundo gay de Lima es pequeño y los encuentros sexuales y amorosos suelen darse entre las mismas personas. 
Los sentimientos predominantes en la narrativa de las jóvenes están vinculados con el amor romántico (Herrera, 2010). Existe, sin embargo, una tensión al considerar que el amor es finito y que no están dispuestas a permanecer en una relación violenta o poco saludable: «Había momentos donde nos hacíamos daño. Y, terminamos, ¿no? O sea, yo me alejaba mucho de ella porque me sentía muy limitada por ella. Porque todo le parecía mal, porque me criticaba mucho» (Ivanna, 24 años). Algunas experimentaron relaciones poco sanas durante el inicio de su vida sexual. Algunos factores que influyeron en que se viesen en estas situaciones, comentan, son no poder compartir con nadie sus inquietudes sobre las relaciones, por temor al rechazo y la discriminación, así como no contar con referentes de amor lésbico en medios masivos y en sus entornos próximos para saber cómo llevar a cabo sus relaciones. Afirman que, actualmente, ya no están dispuestas a pasar por alto situaciones violentas, producto de la idea del amor romántico, mágico y eterno.

Algunas jóvenes manifestaron que, si bien se adaptan a las exigencias de la sociedad al mantener relaciones monógamas, no se sienten conformes con ello: «En nuestra naturaleza no existe la monogamia, pero la hemos implantado en nuestro cerebro porque, al final, nos dicen que eso nos va a hacer feliz y de alguna forma si tanto te la crees, obviamente, si lo consigues, vas a ser feliz» (Paula, 22 años). También permanece la idea de que entre lesbianas existe la posibilidad de crear nuevos códigos para relacionarse, más allá de los patrones de relación heterosexual monógama, que cuenta con un script y pautas de cómo relacionarse (Gagnon y Simon, 2011).

$\mathrm{El}$ amor, en ese sentido, también es representado como prácticas con las que se expresa el afecto. Se trata de manifestaciones simbólicas, como mandarse mensajes de texto, llamarse o darse regalos pensados especialmente para la otra persona, no regalos genéricos: «Sabía que le encantaba un postre. Esperaba que salga de su clase, estaba renegona y darle ese detalle y que le mejore el día» (Antonella, 20 años). Como no suelen demostrar afecto en espacios públicos, lo hacen mediante redes sociales, con posts o fotos en Instagram o Facebook. El amor implica estar para la pareja y contar con ella para compartir proyectos personales, logros y cosas cotidianas que para quien no forme parte de la relación podrían ser insignificantes. Las jóvenes hacen hincapié en que no se debe confundir la compañía y presencia con la invasión en la vida de la otra persona pues, como Thaís sostuvo: «Cuando alguien te presenta 'hola, ella es mi flaca'... ¿Tiene nombre? ¿Es una persona o es solo tu flaca? [...] se confunde un poco eso de compartir espacios con convertir a alguien en tu apéndice» ( 24 años), o, como comentaba Carolina: «Empezamos a convivir muy rápido, ese también fue el problema. Entonces... y yo que valoro mucho mi individualidad como que empecé a ahogarme» (22 años), mantener la individualidad e independencia de cada parte en la relación es sumamente importante para no perderse en ella. 
El amor también se representa como intimidad por la complicidad con la pareja y también en el aspecto sexual. Lo primero responde a los códigos que solo se comparten con la pareja y se vincula con la demostración del afecto. Se trata del goce de la proximidad con la pareja, donde pueden explorar sentimientos y emociones que nadie fuera de esa ecuación puede comprender. En palabras de Ivanna, es «esa sensación de querer compartir, de que sea parte, de intimidad, eso, de intimidad, de hacerla parte de mi vida, de mi mundo, o ella del suyo» (24 años). En el ámbito de la sexualidad, se llega a la intimidad con la pareja por el deseo y la atracción, ya sea en el marco de una relación sexual plástica, que puede durar solo una noche (Giddens, 2014), o como parte un vínculo a mediano o largo plazo. En cualquier caso, las jóvenes comentan que tienen intimidad sexual cuando hay atracción y afecto: «Se levantó [tras tener sexo] y me abrazó. Entonces, como ya me dio la confianza yo, obviamente, la abracé y estuvimos todo el día juntas» (Paula, 22 años). Tener relaciones sexuales implica perder pudor y tener valor para transgredir la norma heterosexual (Elías, 1987): «Es el máximo acto de respeto y de entrega y de amor y al mismo tiempo tiene todo este componente animal» (Ivanna, 24 años). Además, es un acto de placer y goce que no se han encontrado en el intercambio sexual con hombres, pues con ellos no hay esta complicidad que con las mujeres sí.

Para las jóvenes, el amor también es trabajo, pues implica construir un proyecto con esfuerzos individuales y en conjunto con la pareja. El amor se transforma con el tiempo y debe trabajarse en él para que prevalezca y sea sólido, mencionaba Lorena: «Crecemos y creo que también con eso nuestro amor crece, nuestro amor como pareja y como persona [...] Nuestra capacidad de amar también crece y también puede variar» (24 años).

Las jóvenes identifican la mutabilidad del amor y su capacidad de transformación, que puede ser producto tanto de los cambios personales como de las etapas por las que atraviesa la relación. La duración de las relaciones está sujeta a elementos externos y otros individuales. Sin duda, las jóvenes demostraron ánimos de construir relaciones duraderas y sólidas, distintas de las descritas en el «amor líquido» de Bauman (2005). Esto implica ciertos hacer sacrificios y superar los obstáculos que trae ser lesbianas, principalmente con respecto a no poder compartir su relación con sus familiares o en el espacio público. Ser lesbiana tiene consecuencias en la forma en sus experiencias amorosas. Como Carolina comentó, se comienza a amar «un poquito menos» a la pareja por no poder tener muestras de afecto públicas con ella (Carolina, 22 años). En esa línea, Thaís comentaba que la falta de referentes de amor lésbico tuvo efectos positivos: «Yo no sabía cómo era estar con una chica y sentía algunas cosas, pero también, dentro de esa falta de modelos formales, encuentro que hay algo de como sana libertad... como que las reglas que yo puse las puse porque así me sentía cómoda y era lo que quería» (Thaís, 24 años). En otros 
casos, donde las jóvenes mantienen su relación a distancia, el amor se vuelve una promesa. Deben aprender a ceder y comprender que no podrán estar siempre al lado de la pareja.

Otra de las representaciones es el amor como objeto, pues se cristaliza en la persona amada y en la relación: "Amor es... es el otro y eres tú. Es como la conjunción del otro y tú, creo, y es, pucha... pienso en amor y siento y pienso Andrea» (Gracia, 23 años). Se materializa, también, en proyectos en común con la pareja, como estudiar o trabajar en el extranjero, convivir, casarse, tener una familia con o sin hijos. Cabe señalar que predomina el deseo de concretar metas individuales antes de realizar planes en pareja y desean que esta visión de la vida sea compartida por sus parejas. Además, la persona con la que decidan casarse — comentaban algunas de las jóvenes - tiene que ser el amor de su vida: «Una familia debe venir de dos personas que se aman a más no poder, sí o sí. O sea, no creo en las personas que se casan y ves que tienen dudas» (Paula, 22 años). De ahí que el proyecto en común, que implica trabajo, se materialice en un hogar, familia, matrimonio: "Siempre tuve la idea de que me quería casar joven. Porque yo tenía esta idea del 'para siempre' [...] no necesitaba experimentar y vivir y ser una soltera jajaja. No. Quería encontrar a alguien que me dé esa sensación de hogar» (Ivanna, 24 años). El matrimonio es una razón para celebrar con amistades o un contrato civil que implica beneficios legales, pues protege a los integrantes de la familia ante eventualidades. Algunas jóvenes prefieren invertir en un lugar para vivir o un viaje que en una boda: «Preferiría gastar esa plata en viajar con mi novia o pagarnos un techo donde podamos vivir tranquila y esas cosas [...] quizás una pareja homosexual quiera gastar esa plata en un anillo, pero no sé. A mis amigas lesbianas que han tenido relaciones largas nunca las he escuchado preocuparse por ese tipo de cosas, sus prioridades están en otras cosas» (Lorena, 24 años). Esta visión es compartida por sus pares lesbianas.

Las jóvenes representan el amor también bajo la noción de justicia. Esto implica que el sentimiento sea mutuo y que nadie ame más o menos que la otra. Es decir, debe haber equidad en el ir y venir del sentimiento amoroso. La justicia se manifiesta también en el respeto de los acuerdos puestos por la pareja para sacar adelante la relación. Al respecto, comentaba Jacquie: "Cuando uno siente que da más que el otro, no siento que vaya a estar feliz. Y si siente que da menos que el otro es porque, no sé, no se siente lo suficientemente bueno para la otra persona. Supongo que se genera insatisfacción» (23 años). En esta definición del amor como justicia también se manifiesta el amor como prácticas y trabajo para la demostración de afecto y mantenimiento del vínculo. Los acuerdos que la pareja deberá seguir durante la relación pueden ser tomados al inicio de la relación o mutar en el tiempo. Comentaba Gracia, no obstante, que algunos acuerdos pueden no ser negociables en el tiempo, como la decisión de hacer volver la relación monógama en poliamorosa, 
por ejemplo. Cabe señalar que, mientras la relación monógama se da entre dos personas, la poliamorosa se entiende como «una relación entre más de dos personas al mismo tiempo donde todas las personas involucradas consienten y están de acuerdo en la relación» (Enciso, 2018, p. 120). De otro lado, es la predisposición de las jóvenes lo que hará que el vínculo se sostenga en el tiempo, pues el amor es compromiso. "Que la persona considere que es importante estar para la otra persona siempre. O sea, que no te sientas abandonado u olvidado o ese tipo de cosas" (Romina, 24 años).

Ahora bien, las representaciones presentadas se enmarcan en distintos tipos de amor, entre el romántico y el confluente, y en el amor confluente. Estas dos tendencias a una u otra forma de encarnar el amor tiene que ver con las trayectorias familiares, redes y autoidentificación de las jóvenes. En el primer grupo se encuentran Gracia, Paula, Antonella, Ivanna y Carolina; en el segundo, Thaís, Lorena, Jacquie y Romina. Dichas representaciones no son homogéneas: presentan tensiones e implican negociaciones. Además, las jóvenes reflexionan y se cuestionan el amor que llevan a la práctica, mas ninguna lo representa dentro del paradigma del «amor líquido» (Bauman, 2005). En la tabla 4 se resume lo anterior.

Tabla 4. Dos aproximaciones al amor

\begin{tabular}{ll}
\hline $\begin{array}{l}\text { Entre el amor romántico } \\
\text { y el confluente }\end{array}$ & El amor confluente \\
\hline Gracia & Thaís \\
Paula & Lorena \\
Antonella & Jacquie \\
Ivanna & Romina \\
Carolina & - \\
\hline
\end{tabular}

\section{ENTRE EL AMOR ROMÁNTICO Y EL CONFLUENTE}

Gran parte de las jóvenes de este grupo admira las relaciones de sus padres y anhela una vida de pareja como la suya: «Se entienden mucho, que tienen una comunicación, este... muy fluida. Que difícilmente los vas a encontrar peleando [...] Los dos hacen sus proyectos, es como una relación bastante admirable, ¿no? O sea, después de tantos años, como seguir viendo esa... esa relación de amor y de paz» (Carolina, 22 ańos). Ivanna también rescata la comunicación de sus padres y el respeto de sus individualidades, al igual que Carolina: «A pesar de ser distintos y de haberse dicho las cosas en su momento, creo que ninguno nunca pretendió cambiar al otro» (Ivanna, 24 años). 
Ambas quieren tener una familia, donde la relación con la pareja sea similar a las de sus padres. El matrimonio civil y religioso de los padres de Gracia y Paula no se mantiene por estar enamorados, quienes permanecen juntos tras superar conflictos y separaciones. Paula, pese a no imaginarse con una sola persona por el resto de su vida, quiere una familia y pareja estable, a quien ame. Gracia espera tener una relación distinta de la de sus padres, donde prime el amor y no el conflicto ni el maltrato. Ambas manifestaron el deseo de deconstruir la noción de amor que llevan a la práctica: Gracia al intentar ser menos celosa y Paula al «querer desear» las pautas del amor romántico, claves para ser feliz. Antonella, por su parte, tiene como referente de amor la relación de sus tíos, que llevan casados muchos años, no discuten y bromean siempre. Desea una relación como esa para sí, llena de amor con complicidad y compañerismo (Herrera, 2010; Giddens, 1995).

En cuanto a la aceptación de la homosexualidad de las jóvenes, es preciso señalar que los padres de aquellas que "salieron del clóset» les dieron su apoyo, aunque no de inmediato. Algunas reconocieron este soporte como un privilegio, pues no es la realidad de toda la población LGTBIQ. De otro lado, sus redes sociales se integran por amigxs del colegio, del distrito donde crecieron y de la universidad; pero sus mejores amigas y amigos son LGTBIQ, lo que facilitó sus salidas del clóset. Tener amigxs de la comunidad LGTBIQ implica tener libertad para hablar de ciertos temas y ser comprendidas. Es con ellxs con quienes acuden a espacios, como fiestas o discotecas gay, donde se sienten libres de expresar su sexualidad.

En espacios heterosexuales, las expresiones de sexualidades «disidentes» a la norma resultan transgresoras (Elías, 1987); de ahí que acudir a tales espacios resulte una estrategia de "cuidado» o una tecnología del yo (Foucault, 2008) para protegerse y no romper el orden social. Según Elías, son estrategias efectuadas «por cuenta propia o con la ayuda de otros, cierto número de operaciones sobre su cuerpo y su alma, pensamientos, conducta o cualquier forma de ser, obteniendo así una transformación de sí mismos con el fin de alcanzar cierto estado de felicidad, pureza, sabiduría o inmortalidad» (1987 p. 48). De ahí también que Gracia sea la única que se identifica como «lesbiana", pues siente "la necesidad de luchar, de visibilizar» (Gracia, 22 años). Esto entra en tensión con el temor al rechazo de sus padres, quienes no saben que es lesbiana. Para el resto, la categoría no ha sido motivo de cuestionamiento, por lo que se autoidentifican como «leca».

Se puede inferir, entonces, que se han interiorizado las tecnologías de poder de las instituciones en las que están inscritas y reproducen pautas sociales que implican no visibilizarse como lesbianas y reproducir el amor romántico, aunque se cuestionen algunas de sus prácticas (Herrera, 2018, p. 19). Las jóvenes de este grupo asumen y reproducen estereotipos de género binario en sus representaciones del amor. Es decir, se asignan atributos tradicionalmente femeninos o masculinos, 
como ser pasivas o activas, tanto fuera como dentro del plano sexual: «La activa es la que invita, la que, no sé, no sé, bueno, el plano sexual también, ¿no? La que da... la pasiva es la que recibe» (Carolina, 22 años). Pueden ser modernas o versátiles, también, lo que implica ejercer ambos roles o pasar sin problema de uno a otro. Además, se denomina «leca densa» a quienes son muy emocionales, sensibles, entre otras cualidades tradicionalmente vinculadas con la feminidad (Fuller, 1993). Comentaba Carolina. «Estamos replicando modelos en vez de construir» (23 años). Esta conciencia sobre las contradicciones de replicar estereotipos binarios en el mundo gay despierta en algunas la necesidad de replantearse cómo representan sus afectos, con el objetivo de acercarse a un modelo de amor más equitativo.

Las primeras relaciones se vieron atravesadas por dependencia emocional, peleas, inseguridades y celos; fueron llamadas relaciones tóxicas. Encontrarse en estas fue producto usualmente de la falta de referentes de amor lésbico y la carencia de redes de soporte donde conversar sobre el tema y aconsejarse. Así también, por las tensiones experimentadas al transgredir los patrones de clase y género que se esperaba que cumplieran. En la actualidad, la mayoría está en una relación y es consciente de los cambios que ha tenido que atravesar para no volver a una relación tóxica. Actualmente, todas están fuera del clóset con sus grupos de pares y cuentan con soporte de ellxs para discutir sus dudas, problemas y cuestionamientos en torno a sus sexualidades y relaciones de pareja. Cabe señalar que, además, la mayoría tiene también el apoyo de sus padres. Las relaciones que tienen hoy en día son algunas más largas que otras, pero no por ello menos significativas, como se puede ver en la narrativa de Gracia: "Cuando empezamos a salir ya era como lo que sentíamos la una por la otra era demasiado fuerte [...] ya en nueve días cumplimos dos meses» (Gracia, 22 años). Esto se vincula a la idealización de la pareja y el sentimiento amoroso. Este es distinto del que se siente al tener encuentros sexuales plásticos. Antonella, por ejemplo, comentaba que sus expectativas y prácticas no son similares en uno y otro caso. Como se puede ver, confluyen características del amor romántico con otras del amor confluente. Esto se hace evidente cuando las jóvenes piensan en torno al tiempo que durará la relación, así como en lo que esperan y están dispuestas a dar en ella.

\section{El amor confluente}

En este grupo se ha encontrado que solo los padres de una de las jóvenes no están casados. El resto mantiene el vínculo, aunque estén enamorados, salvo en el caso de los padres de Thaís. Se encontró que ellos sí están enamorados y llevan una buena relación, comunicativa y sin conflictos. De ahí que la joven anhele una relación como esa, mientras que se alegra de no tener que encajar en el modelo de una 
relación heterosexual. En el resto, la relación conflictiva de sus padres ha influido en que sus proyectos de vida contemplen la convivencia antes que casarse. Las que prefieren la vía del matrimonio, como Romina, comentaron que sería solo por los beneficios legales y de protección a los hijos. Mientras tanto, sus pares heterosexuales tienen expectativas distintas: esperan casarse e invierten grandes cifras en anillos de bodas, continúa siendo un mandato de clase. Las jóvenes de este grupo preferirían viajar o comprar un departamento con ese dinero. Reflexionan sobre el matrimonio como institución del amor romántico, cuya única utilidad real es la del amparo legal. Jacquie no lo considera una prioridad, igual que tener hijos. Se distancia del matrimonio como meta mientras aparenta con sus padres ser bisexual para "darles una esperancita» (23 ańos) de que tendrá una vida "normal», con esposo e hijos, propia de la clase alta y la feminidad tradicional.

$\mathrm{Al}$ igual que Jacquie, el resto de las jóvenes en este grupo prioriza sus proyectos personales antes que aquellos con las parejas o ven la manera de llevar a cabo ambos en simultáneo. Todas, además, son conscientes de la finitud potencial de sus vínculos y mantienen una búsqueda constante por la equidad en la relación, como ocurre en el amor confluente (Giddens, 1995). Cabe señalar que todo esto se encuentra enmarcado en relaciones familiares con padres machistas: como Lorena comentaba, «esperan que tenga hijos, me case. Mi papá tiene ese tipo de expresiones de 'pero ¿cómo no vas a saber cocinar? Cuando te cases, ¿qué vas a hacer?'” (24 años). Una de ellas tiene el apoyo de sus padres para que su orientación sexual no sea causal de conflicto o malestar para ella o su pareja. Reconoce esto como un privilegio. Además, esto influye en que pueda reflexionar con la posibilidad de ejercer un amor no romántico, posesivo y heteronormativo. En ella, como en otras de las jóvenes de este grupo, se produce un rechazo y distanciamiento de estos mandatos, así como de otros vinculados a los roles de "activa" $\mathrm{y}$ "pasiva" vistos previamente, que sí son asumidos por algunas de sus amigas, por las ansias por vincularse de un modo más equitativo, con conocimiento pleno de la otra persona y respeto a las individualidades (Giddens, 1995).

Como en el grupo anterior, resalta aquí la importancia del círculo de amigxs LGTBIQ, pues es con quienes se sienten libres para expresar su sexualidad y conversar sobre sus experiencias. Es por ello que también acuden a establecimientos y fiestas gay, donde suelen conocer a sus parejas románticas o sexuales, lo que da cuenta de la homogamia (Maenpaa y Jalovaara, 2013) del grupo de jóvenes lesbianas de sectores altos de Lima, donde compartir un habitus, capital simbólico y cultural similar, influye directamente en las posibilidades de vincularse sexual o románticamente con alguien. Además, es en estos espacios donde pueden transgredir la norma heterosexual sin ser juzgadas o verse en una situación de vulnerabilidad por ser lesbianas. En algunos casos, recurren también al uso del alcohol para tener encuentros 
físicos con otras mujeres: «Disfruto las relaciones sexuales cuando me gusta alguien en verdad, no solo físicamente, sino como que en verdad me gusta. Entonces, si no me gusta en serio, si es que ha pasado, ha sido por la culpa del alcohol» (Jacquie, 23 ańos). Tanto los espacios y fiestas gay constituyen tecnologías del yo (Foucault, 2008), que reconocen el poder de la heterosexualidad normativa de Lima, pero encuentran salidas para continuar disfrutando de su sexualidad sin poner en riesgo su integridad ni el orden de clase.

Por otro lado, ni las jóvenes ni sus redes pertenecen a grupos activistas, aunque algunas hacen ciberactivismo y acuden a marchas multitudinarias por los derechos LGTBIQ. Varias comentaron que hacen "activismo cotidiano", a través del diálogo con otros sobre diversidad sexual y equidad de género, así como con ser out. Esto implica no ocultar su identidad de género ni su orientación sexual. Thaís y Lorena, por su parte, hicieron hincapié en la necesidad y ansias por trabajar por la equidad de género desde sus vidas profesionales. Mientras tanto, en las narrativas se encuentra que la falta de involucramiento en el activismo responde a no haber sido víctimas de violencia por su orientación sexual. Ellas reconocen esto como privilegio que responde, en parte, a su posición social, color de piel y atractivo físico:

Físicamente pasaba más piola y eso, de cierta manera, igual es un privilegio porque, de pronto, la gente me encasilla más dentro del grupo de las primeras lesbianas... «ay, son lindas, y cachan ${ }^{13}$ todo el día, me encantan» [...] sobre ese grupo no hay como tanto rechazo, entonces, por ahí quizás también ese privilegio de como mi apariencia y... mmm... igual supongo que vivo en una zona segura (Thaís, 24 años).

El anhelo por construir nuevas formas de relacionarse entra en tensión con los límites que se imponen para protegerse con las tecnologías del yo. Se continúan cuestionando si es normal expresar su amor en el espacio público e identificarse como lesbianas abiertamente, por lo que se inhiben ante posibles consecuencias, tales, como ser discriminadas o agredidas. De ahí que, como en el grupo anterior, no se autoidentifiquen con la categoría "lesbiana»: "lesbiana" me suena como que súper fuerte» (Jacquie 23 años). Mencionaba Elías (1987) que la transgresión en el lenguaje equivale a la transgresión también de la cultura. Denominarse «leca» sería, por lo tanto, un recurso que opera a manera de tecnología del yo (Foucault, 2008) con el que se protegen de la discriminación por transgredir el orden social en el entorno conservador del sector alto de Lima, que se rige por normas tradicionales de vivir la sexualidad, en la matriz heterosexual y de amor romántico.

13 Tienen sexo. 
Romina, por su parte, no deja de autoidentificarse como «leca», pese a estar en una relación con un hombre: «Me identifico y soy eso [...] si me dicen 'puedes volver a nacer y decidir ser heterosexual o gay', igay toda la vida!» (24 años). Es preciso considerar que la identidad sexual y de género se construyen mediante la repetición de actos performativos, fuera del orden de género binario y heteronormativo (Butler, 1990). De ahí que no corresponda a la investigadora o a la sociedad categorizar a las personas a partir de estructuras ajenas a la experiencia propia, pues es una forma de ejercer violencia simbólica (Bourdieu, 1999).

\section{LOS SECRETOS EN EL AMOR LÉSBICO}

Durante la realización de estudio, se identificaron secretos que dan cuenta de la especificidad del amor entre estas jóvenes lesbianas. Los secretos cumplen la función de motor en las interacciones sociales, permiten que estas se den sin incomodidades (Simmel, 2010) que, en este caso, pudieran ser producto de identificarse en una orientación sexual «disidente» de la heterosexual, normativa en el sector alto de Lima. Se trata del secreto del mundo interno, con el entorno y con la pareja, que giran en torno al núcleo del amor, como se puede ver en el gráfico 2. Es preciso señalar que estos secretos pueden existir en otras poblaciones. Es posible, también, que algunos respondan al hecho de pertenecer a los sectores altos de Lima o a una cuestión generacional. No obstante, la particularidad del secreto aquí es que responde a las necesidades de sujetos que, además, tienen una orientación sexual no normativa. Estos sujetos, además, atraviesan cuestionamientos y se plantean para sí proyectos afectivos en el marco de la diversidad sexual.

\section{Gráfico 2. Secretos en el amor lésbico}

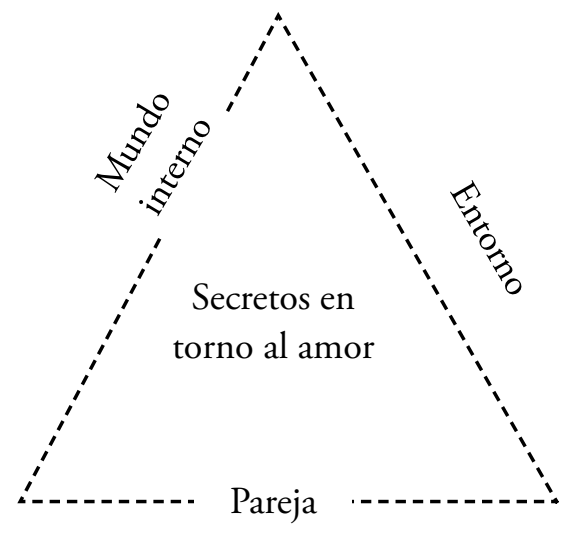


Para develar estos secretos fue esencial construir un clima de confianza que les diera seguridad a las jóvenes para compartir sus historias. De ahí la importancia de las gatekeepers, quienes facilitaron el primer contacto entre la investigadora y participantes; el ambiente donde se llevaron a cabo las entrevistas, usualmente al aire libre, lejos de otras personas que pudieran escuchar las conversaciones; del lenguaje empleado, y de la necesidad de las jóvenes por expresar aquello que no suele ser contado, pero que precisan compartir con quien no forme parte de las diásporas de los tres secretos.

El secreto del mundo interno estuvo presente en Thaís, Paula y Carolina. Se trata de deseos vinculados con la vivencia de su sexualidad y el amor que no han podido contar previamente y logran confiar durante las entrevistas. Por ejemplo, el de aspirar a tener relaciones abiertas, poliamorosas u orientadas hacia el amor líquido. Paula rompe el secreto en la entrevista cuando comenta que quiere querer un amor como el romántico, pues ha internalizado los mitos del amor romántico que, comenta, la harán feliz. De ahí que, aunque le resulta aburrido, desee una familia y pareja para siempre. Carolina también desea explorar la posibilidad de vivir libre de los constreñimientos de la monogamia para ser «más consecuente» con su perspectiva sobre de las relaciones y cómo las lleva a la práctica. Thaís no ha negociado con su pareja los acuerdos que seguirán. Plantearse una relación poliamorosa o líquida la aleja del modelo de amor de las relaciones amorosas que admira, románticas o confluentes. Supone, también, transgredir mandatos de clase. Durante el inicio de las relaciones sexuales y afectivas de las jóvenes, encuentran pocos espacios para la reflexión sobre sus relaciones pues, como mencionó Thaís, tienen otras preocupaciones como identificarse como lesbianas; salir del clóset, conocer sus cuerpos en el intercambio sexual, sin haber tenido referentes de relaciones lésbicas; evitar ser discriminadas, entre otras. Algunas, además, esperan poder regresar a un modelo de amor romántico que les permita casarse y formar una familia para satisfacer las expectativas de su entorno.

El segundo secreto, de la familia y el entorno, ocurre cuando se oculta a estos actores la identidad lésbica. Estuvo presente en la narrativa de la mayoría de jóvenes — Jacquie, Paula, Ivanna, Carolina y Gracia—, pues se trata del cuidado que guardan para evitar exponerse a riesgos que atenten contra su integridad. Ello implica mantener su vida afectiva y relaciones ocultas de la familia o la sociedad. Ocultar este secreto por temor a no poder compartir con nadie sus experiencias afectivas, especialmente a temprana edad, puede desencadenar en que el amor se vuelva dependiente y poco sano, como comentaba Paula:

Se empezaron a arruinar mis relaciones con mis amigos del colegio por este tema, por no poder contarles. Y Marcela comenzó a aislarse para no tener este tipo de 
conversaciones con la gente, entonces ya la relación, en verdad, después de tres años de esto mismo, al final se fue arruinando porque ya éramos muy codependientes de la una a la otra, ya, nosotras contra todo (Paula, 22 ańos).

Se produce el aislamiento del entorno y con ello se desarrollan relaciones con dependencia emocional. Este es uno de los extremos a los que se puede llegar con el amor romántico, que subordina a las mujeres: «Son cientos los miedos que se nos meten en el cuerpo: [...] miedo a salir del armario y a reivindicar nuestro derecho a amar a quien queramos y como queramos» (Herrera 2018, p. 18). Durante las primeras relaciones con mujeres, la dificultad para develar el secreto en el entorno familiar o institucional (escuelas, clínicas, entre otros) sin ser juzgadas o discriminadas repercute en el bienestar de los sujetos y de la relación. Deviene «una alianza de dos contra el mundo, y se confunde ese egoísmo à deux con amor e intimidad» (Fromm 2016, p. 119).

Transgredir el orden del espacio público o las tradiciones en una familia donde las normas de comportamiento son vigiladas deviene en reprimendas que van desde el juicio moral hasta otras formas de violencia. Por ello, este grupo de jóvenes lesbianas de sectores altos prefiere cuidarse mediante una baja exposición de su orientación sexual en público y se reservan las manifestaciones de afecto lésbicas para ambientes gay. De ahí también que la mayoría opte por no visibilizarse mediante el activismo por los derechos LGTBIQ y prefiera mantenerlo en el ámbito virtual, profesional o de la vida cotidiana. Cuando viajaron a países donde la homosexualidad es aceptada socialmente y el Estado es garante de derechos, experimentaron una libertad que les permitió expresar sus afectos libremente y sin temores, tal como relataba Martel (2013) sobre la relación entre la población LGTBIQ y diversas ciudades en el mundo.

El último secreto estuvo presente en las narrativas de Paula, Carolina y Gracia. Se trata de aquel que se guarda de la pareja para evitar lastimarla o dañar la relación. Como sostiene Simmel, el secreto contribuye a la reproducción de las relaciones sociales (Simmel, 2010). En este caso, debido a que se ha aprendido que es más saludable no contarlo todo para que ambas partes de la relación tengan tranquilidad y puedan «descansar y dejar de buscar» otra pareja (Bauman, 2005, p. 33). Se trata de mantener ocultas cuestiones como los celos, aquellos que siente Gracia por ver a su enamorada con su ex; el encuentro sexual de Paula con otra persona durante una ruptura con su pareja, o las ganas de pasar de una relación monógama a una poliamorosa. Comentaba una de las jóvenes que, por lo pequeño que es el mundo gay, estos secretos pueden revelarse como rumores y producir conflictos que lleven a la pareja a la violencia emocional o física. Se encuentra aquí que es preferible no contradecir a la pareja para evitar conflicto (Bauman 2005, pp. 33-34), por lo que se oculta a la pareja los secretos del mundo interno. Esto limita el espacio para la 
reflexión y puesta en práctica de distintas formas de relacionarse, incluso cuando ello implique transgredir normas sociales, como el amor romántico y heterosexual.

Se puede deducir que el grupo de jóvenes lesbianas necesita contar con derechos que les permitan experimentar sus afectos abiertamente, sin temor a visibilizarse en el espacio y a crear nuevas formas de vincularse.

\section{AproximaCiones finALES}

En este artículo se presentaron las representaciones sociales en torno al amor de un grupo de jóvenes lesbianas pertenecientes a los sectores altos de Lima. Esta tarea se llevó a cabo mediante el análisis de sus biografías y considerando la influencia de los cambios globales y locales en la construcción de sus subjetividades. Todos ellos, pues, han influido de alguna manera en cómo ellas se vinculan con la otra afectiva y sexualmente, cómo experimentan sus afectos y cómo representan el amor. El amor encarnado por las jóvenes dista de ser líquido o poliamoroso y se ubica, más bien, entre el amor romántico y el confluente. Ellas han reflexionado en torno a practicar el amor líquido o el poliamor, pero no les ofrece la estabilidad que necesitan emocionalmente ni para desenvolverse en el sector alto limeño, donde ser lesbiana implica la transgresión de valores y normas. El deseo de mantener una relación a largo plazo, monógama, que calce dentro de la matriz de amor romántico o confluente puede ser una estrategia para no transgredir las pautas sociales y preservar su integridad. El amor de las jóvenes se orienta hacia dos tipos: del amor romántico al confluente y en el amor confluente. De ahí que las representaciones del amor como sentimiento, trabajo, objeto, prácticas, intimidad y justicia esté presente entre todas las jóvenes, aunque no de manera homogénea. Esto se debe a que están mediadas por sus subjetividades, trayectorias familiares, redes sociales y autoidentificación.

La mayoría se autoidentificó como «leca», lo que da cuenta de la interiorización de las pautas de reproducción social donde ser lesbiana implica transgredir la norma heterosexual. En el primer grupo, cuando el amor fluctúa entre romántico y confluente, el deber ser se manifiesta también en la reproducción de roles binarios de género como ser pasiva, activa o «leca densa». El amor lésbico transgrede la norma heterosexual, mas no necesariamente el orden binario del género. Admiran y anhelan para sí mismas una relación con rasgos del amor romántico, como las de sus padres o tíos, cuando son sanas, y predomina la comunicación y el respeto. Pocas cuestionan la monogamia y mucho menos la transgreden. Temen que el amor se vuelva tóxico por la dependencia emocional, celos e inseguridades. Algunas reflexionan en torno a la reproducción de dicho orden, pero manifiestan lo difícil que es cambiar el modo en el que operan. A las jóvenes del segundo grupo les gustaría casarse y tener hijos, aunque esto no es central en sus proyectos personales. Ellas rechazan idea de 
la pareja como "apéndice», sin individualidad e independencia frente a la pareja. Prefieren relaciones equitativas, donde las metas y realización personal sean prioritarias. Consideran que, para ello, deben negociar lo que les gusta o no en la relación y trabajar en ella para que perdure en el tiempo.

De otro lado, cuestionan los roles de género binario y no emplean las categorías de activa, pasiva o «leca densa». Demuestran, con el uso que hacen del lenguaje, que tienen la capacidad de recrear la cultura. Reflexionan, también, en torno al privilegio que supone contar con una red de soporte y tener confianza en instituciones para denunciar potenciales agresiones debido a su orientación sexual; sin embargo, prefieren «cuidarse» de exponerse en el espacio público como tal, por lo que prefieren también dejar el trabajo por la equidad para el ámbito profesional y no el activismo. Se encuentra aquí que la inacción opera como una herramienta para el mantenimiento del orden social de la clase alta limeńa a la que pertenecen. En ambos grupos se hicieron presentes tecnologías del yo que les permitieron "cuidarse» de potenciales riesgos a su integridad por ser lesbianas o iniciarse sexualmente sin culpas por transgredir el orden heterosexual y los valores del sector alto. Es así que se encontró el consumo de alcohol como parte del descubrimiento de su sexualidad; que se autoidentifiquen como «leca» o gay; y que no demuestren afecto en espacios públicos o no gayfriendly para evitar ser discriminadas o «sacadas del clóset».

Se encontraron en las narrativas tres los secretos en el amor lésbico. El del mundo interno tiene que ver con ocultar deseos de experimentar relaciones abiertas o poliamorosas. Son pulsiones que surgen en el desarrollo de las entrevistas y que dan cuenta de la represión que experimentan las jóvenes por no transgredir las normas de la clase alta. El secreto que se oculta de la pareja tiene que ver con mantener oculto el primer secreto, así como los deseos de abrir la relación, de vivir un amor vinculado con el amor líquido y alejado de los márgenes del amor romántico monógamo en el que están inscritas. Tiene que ver, también, con no comentar cuestiones del pasado sexual y afectivo, pues esto implicaría tensiones en la seguridad que otorga la monogamia y exclusividad. Podría, además, implicar inseguridades y celos, así como el inicio de peleas y una relación tóxica. Quizá algunos de estos secretos puedan encontrarse en otros sectores de la población. Es preciso, en esta oportunidad, comprender las implicancias de los secretos en la vida de las jóvenes lesbianas. De facto, serían distintas a aquellas a las que se podría enfrentar una persona heterosexual, cisgénero, hombre o mujer, de un sector que tradicionalmente no presta la misma importancia a la reproducción y mantenimiento del orden social que le dan los sectores altos. Por último, está el secreto del entorno, que se guarda de la familia e instituciones. Develarlo podría ponerlas en riesgo de ser discriminadas o agredidas, de ahí que expresen sus sexualidades en espacios seguros y con redes de confianza; que no salgan del clóset con sus familias o que lo hagan como bisexuales 
y no lesbianas. De ahí que mantener los tres secretos sea también una tecnología del yo que las jóvenes emplean para proteger su integridad y no romper el orden de clase, pues ser lesbiana en Lima implica una doble transgresión: a la norma heterosexual y a los mandatos de clase, donde predomina el amor romántico.

Queda pendiente la tarea de ahondar en las experiencias afectivas y sexuales de jóvenes lesbianas de otros sectores socioeconómicos y espacios geográficos, así como entre sujetos y colectivos con distintas orientaciones sexuales. Esperamos que este artículo haya despertado preguntas y curiosidades que puedan ser resueltas en los años por venir, para seguir contribuyendo en el conocimiento de las diversidades y los universos del amor.

\section{REFERENCIAS BIBLIOGRÁFICAS}

Asociación Peruana de Empresas de Inteligencia de Mercados - Apeim (2016). Niveles socioeconómicos 2016. Lima: Apeim.

Aramburú, C. (2012). Una población diferente: cinco décadas de cambio. En O. Plaza (ed.), Una población diferente: cinco décadas de cambio. Homenaje a Denis Sulmont (p. 55-72). Segunda edición. Lima: Fondo Editorial de la Pontificia Universidad Católica del Perú.

Arfuch, L. (2002). El espacio biográfico. Dilemas de la subjetividad contemporánea. Buenos Aires: Fondo de Cultura Económica.

Bauman, Z. (2005). Amor líquido. Acerca de la fragilidad de los vínculos humanos. México, D. F.: Fondo de Cultura Económica.

Beck, U. y E. Beck (2001). El normal caos del amor. Las nuevas formas de la relación amorosa. Barcelona: Paidós.

Bourdieu, P. (1999). Comprender. En La miseria del mundo. Buenos Aires: Fondo de Cultura Económica.

Butler, J. (1990). El género en disputa. Nueva York: Routledge.

Elías, N. (1987). El proceso de la civilización: investigaciones sociogenéticas y psicogenéticas. México, D. F.: Fondo de Cultura Económica.

Enciso, G. (2018). La gran pregunta de los celos: comprendiendo el poliamor. En S. Cendal (ed.), (h)amor3. Madrid: Continta Me Tienes.

Faur, E. y Grimson, mA. (2016). Mitomanías de los sexos. Ideas del siglo XX sobre el amor, el deseo y el poder que necesitamos desechar para vivir en el siglo XXI. Buenos Aires: Siglo XXI.

Foucault, M. (2008). Tecnologías del yo. Buenos Aires: Paidós.

Fromm, E. (2016). El arte de amar. Una investigación sobre la naturaleza del amor. Lima: Paidós.

Fuller, N. (1993). Dilemas de la femineidad. Mujeres de clase media en el Perú. Lima: Fondo Editorial de la Pontificia Universidad Católica del Perú. 
Gagnon, J. y Simon, W. (1973). Sexual Conduct: The Social Sources of Human Sexuality. New Brunswick, NJ: Transaction Publishers.

García, A. (2013). Una lectura del amor desde la sociología: algunas dimensiones del análisis social. Sociológica, 80, 155-188.

Giddens, A. (1995). La transformación de la intimidad. Madrid: Cátedra.

Giddens, A. (2014). Sociología. Madrid: Alianza Editorial.

Glaser, B. y Strauss, A. (1967). The discovery of grounded theory. Chicago: Aldine Press.

Haraway, D. J. (1991). Simians, cyborgs, and women: The reinvention of nature. New York: Routledge.

Haraway, D. J. (1994). A manifiesto for cyborgs: Science, technology and socialist feminism in the 1980s. En S. Seidman (ed.), The postmodern turn: new perspectives on social theory (pp. 82-116). Cambridge: Cambridge University Press. https://doi. org/10.1017/CBO9780511570940.007

Herrera, C. (2010). La construcción sociocultural del amor romántico. Madrid: Fundamentos.

Herrera, C. (2013). El amor romántico desde la perspectiva queer. Madrid: El Rincón de Haika.

Herrera, C. (2018). La culpa, los miedos y el amor romántico patriarcal. En S. Cendal (ed.), (b)amor3. Madrid: Continta Me Tienes.

Huber, L. y Lamas, L. (2017). Deconstruyendo el rombo. Consideraciones sobre la nueva clase media en el Perú. Lima: Instituto de Estudios Peruanos.

Ilizarbe, C. (1999). Todavía no somos quienes queremos ser: Construcciones sociales del amor en la pareja en jóvenes de sectores medios en Lima. En Aldo Panfichi y Marcel Varcárcel, Juventud, sociedad y cultura (pp. 471-505). Lima: Red para el Desarrollo de las Ciencias Sociales en el Perú.

Illouz, E. (2009). El amor y la utopía romántica. El amor y las contradicciones culturales del capitalismo. Madrid. Safekat. https://doi.org/10.2307/j.ctvm7bc9h

Instituto Nacional de Estadística e Informática (2016). Encuesta Demográfica y de Salud Familiar. Lima: Instituto Nacional de Estadística e Informática. Recuperado de https://www.inei.gob.pe/media/MenuRecursivo/publicaciones_digitales/Est/ Lib1433/index.html

Instituto Nacional de Estadística e Informática (2017). Sistema de información regional para la toma de decisiones. Lima: Instituto Nacional de Estadística e Informática. Recuperado de http://webinei.inei.gob.pe:8080/SIRTOD/inicio.html\#

Instituto Nacional de Estadística e Informática (2017). Sistema de información regional para la toma de decisiones. Lima. Recuperado de http://webinei.inei.gob.pe:8080/ SIRTOD/\#app=8d5c\&d4a2-selectedIndex=0\&d9ef-selectedIndex $=1$

Ipsos (2014a). Unión civil homosexual en el Perú. Encuesta nacional urbana-abril 2014. Lima. Ipsos (2014b). Perfiles socioeconómicos Perú 2014. Lima.

Jodelet, D. (2011). Aportes de las representaciones sociales al campo de la educación. Espacios en Blanco. Serie indagaciones, $\mathrm{N}^{\circ} 21$ - junio de 2011 (133-154). Recuperado de http://www.scielo.org.ar/pdf/eb/v21n1/v21n1a06.pdf

Kogan, L. (2009). Regias y conservadoras. Lima: Fondo Editorial del Congreso. 
Maenpaa, E. y Jalovaara, M. (2013). The effects of homogamy in socio-economic background and education on the transition from cohabitation to marriage. Acta Sociológica. 2013, 56(3), 247-263. https://doi.org/10.1177/0001699312474385

Martel, Frederic (2013). Global gay. Cómo la revolución gay está cambiando el mundo. Lima: Penguin Random House Grupo Editorial.

Menéndez, P. (2014). Transformaciones de las prácticas amorosas de los jóvenes de las nuevas clases medias y populares de Lima Norte. Tesis de licenciatura en Sociología. Lima: Universidad Nacional Mayor de San Marcos, Facultad de Ciencias Sociales.

No tengo miedo (2016a). Cartilla para la incidencia sobre políticas públicas para la garantía plena de los derechos humanos de las personas LGTBIQ+. Lima.

No tengo miedo (2016b). Nuestra voz persiste: diagnóstico de la situación de personas lesbianas, gays, bisexuales, transgénero, intersexuales y queer en el Perú. Lima: Tránsito - Vías de Comunicación Escénicas.

Organización Mundial de la Salud (2000). Informe de un grupo de estudio de la OMS acerca de los jóvenes y la salud para todos en el año 2000. Ginebra.

Rodríguez, T. y Pérez, R. (2006). Representaciones sociales del amor en jóvenes urbanos. Ciudad: Editorial.

Sara-Lafosse, V. (2012). Hacia la equidad de género y la democratización de la familia. En Cambios sociales en el Perú (pp. 325-346). Segunda edición. Lima: Fondo Editorial de la Pontificia Universidad Catolica del Perú

Segato, R. (2011). Género y colonialidad: en busca de claves de lectura de un vocabulario estratégico descolonial. En Karina Bidaseca y Vanesa Vázquez. Feminismos y poscolonialidad: descolonizando el feminismo desde y en América Latina (pp. 17-47). Buenos Aires: Godot. https://doi.org/10.4000/eces.1533

Sharma, S. (2008). Back, Less: The art of listening. En Book reviews. The British Journal of Sociology, 2008, 59, 3. https://doi.org/10.1111/j.1468-4446.2008.00209_2.x

Simmel, G. (2010). El secreto y las sociedades secretas. Madrid: Sequitur.

Strauss, A. y Corbin, J. (2002). Bases de la investigación cualitativa. Técnicas y procedimientos para desarrollar la teoria fundamentada. Antioquia: Editorial Universidad de Antioquía. 